Asian Social Work Journal (ASWJ), Volume 6, Issue 5, (page 1 - 10), 2021

DOI: https://doi.org/10.47405/aswj.v6i5.179

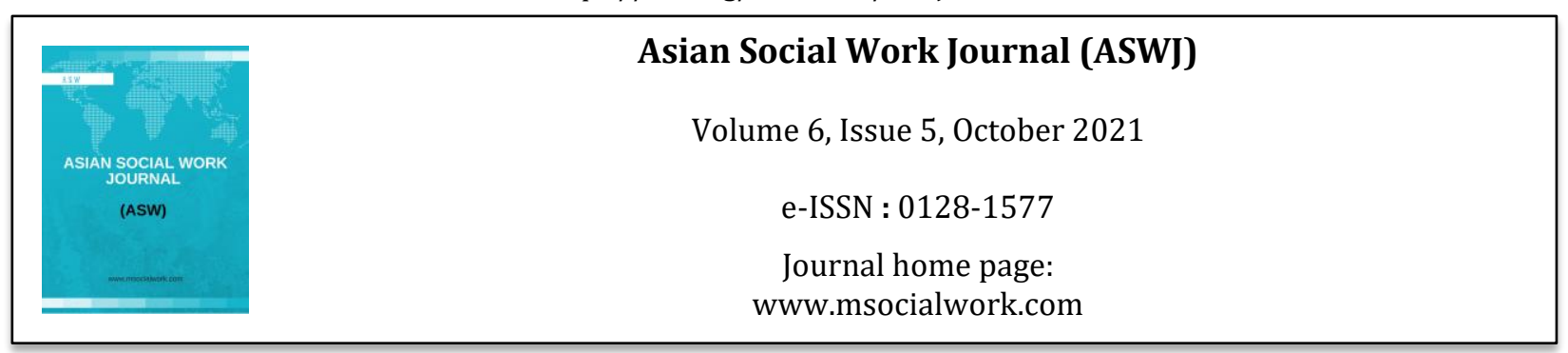

\title{
Do Homeless People Giving Up Hope? A Qualitative Study in Penang, Malaysia
}

\author{
Syazwani Drani' ${ }^{1}$, Azlinda Azman ${ }^{1}$, Paramjit Singh Jamir Singh ${ }^{1}$ \\ ${ }^{1}$ Social Work Department, School of Social Sciences, Universiti Sains Malaysia, 11800 Penang, Malaysia
}

Correspondence: Syazwani Drani (syazwanid@usm.my)

\begin{abstract}
This qualitative study aims to explore the lives of homeless people around Georgetown, Penang, Malaysia especially in the social support aspect of their lives. Twenty (20) informants were involved in this study. Data obtained were analyzed using the content analysis method. The results showed that the homeless were classified as those who had given up hope. Lack of social support resources makes the homeless' lives to be drifted and then further triggers risky behaviour changes. The feelings of isolation and neglect caused the homeless to decide not to have any kind of relationship with their nuclear family. This study has the potential to contribute to the knowledge of social marginalization issues affecting homeless people in Malaysia in general and especially in Georgetown, Penang as well as its implications for the survival and sustainability of these minorities' lives.
\end{abstract}

Keywords: social exclusion, family support, people who had given up hope

\section{Introduction}

The phenomenon of homelessness is a global issue that is continuously being addressed and discussed by all levels, be it at the micro (interactions between individuals), meso (interaction between groups of people), or macro levels (interaction in societies at large). The state of homelessness indirectly affects the psychosocial of the individual involved. In Malaysia, homeless people can be found in several states. These are in the Federal Territories of Kuala Lumpur, Selangor, Pulau Pinang, and Johor (Authors Own, 2016).

The homeless' presence in metropolitan areas can be seen in places where they commonly congregate in public spaces which is usually occupied by a crowd of people. This situation in which their appearance in spotted in public are also similarly being reported by other researchers worldwide. Common factors contributing to their state of homelessness that are often stated by the respondents are aspects of poverty, familial conflicts, inability to pay expensive rent rate, economic problems, sudden unemployment, and many more. These homeless' social problems had been critically and analytically observed by researchers in former discourses.

Anjung Singgah is an initiative by National Welfare Foundation (YKN) to help protect and empower the homeless through mentorship and career programs as well as through motivation and counselling sessions. Of the five Anjung Singgah in Malaysia, 6,936 voluntary check-ins have been successfully recorded since it was established in 2011 (Dewan Rakyat, 2019). This would be a drastic increase if one were to take into account the number of homeless people who have not registered through Anjung Singgah, which in such cases were those living on the streets, or those who have been rescued by the 
Asian Social Work Journal (ASWJ), Volume 6, Issue 5, (page 1 - 10), 2021

DOI: https://doi.org/10.47405/aswj.v6i5.179

Social Welfare Department (JKM) and are placed in the Desa Bina Diri institution, as well as cases being referred to by relevant agencies after these homeless went through some screening process.

The Malaysian Social Welfare Department (2016) recorded a total of 1,048 homeless in 2013 with a break down in 730 men and 318 women, respectively. Consequently, in 2014, there were a number of 1,469 homeless out of 988 men and 481 women. In the following 2015, the number of homeless in the target area further increase to 1,527 people, which involved 1,003 men and 524 women. The number of homeless recorded in Malaysia is stated in Table 1 below.

Table 1: Total Statistics of Homeless People in Malaysia for the Year 2013-2015

\begin{tabular}{lccc}
\hline Year & Total of Homeless People & \multicolumn{2}{c}{ Gender } \\
\hline & & Male & Female \\
\hline 2013 & 1048 & 730 & 318 \\
2014 & 1469 & 988 & 481 \\
2015 & 1527 & 1003 & 524 \\
\hline Total & 4044 & 2721 & 1323 \\
\hline
\end{tabular}

Source: Department of Social Welfare, Malaysia (2016)

Georgetown, Pulau Pinang is one of the cities with a relatively high number of homeless recorded besides Kuala Lumpur, Selangor, Johor, and Sarawak. Pulau Pinang is considered a "honey pot" for homeless individuals because they could source a relatively high income as a homeless. The geographical factors of Pulau Pinang itself as a tourism spot for tourists from various countries are also seen as a contributing element to these homeless in garnering their incomes as these tourists are generous in giving donations to them.

According to statistics obtained from the Penang Social Welfare Department (2019), the number of homeless recorded from 2015 to 2019 had risen to 2,256 in this state. In 2015, there was a further addition in 327 people, and in 2016 and 2017, the number of homeless was seen to be increasing in each consecutive year. In 2016, from the total of homeless recorded, there were new cases amounted to 521 homeless, and this escalates with another 117 new cases of homeless being recorded, bringing the total to 638 homeless recorded in 2017. However, this figure is shown to be declining in 2018. Only 183 homeless people have been recorded as Penang Social Welfare Department had conducted rescue operations regularly. However, this figure rises sharply in 2019 as the number of homeless in Pulau Pinang increase to 587 people. Table 2 below shows the tabulation of homeless people from 2015 to 2019, as recorded by Penang Department of Social Welfare.

Table 2: Total Population Statistics in Penang for the Homeless People in the Year 2015-2019

\begin{tabular}{cc}
\hline Year & Total of Homeless People \\
\hline 2015 & 327 \\
2016 & 521 \\
2017 & 638 \\
2018 & 183 \\
2019 & 587 \\
\hline Total & 2,256 \\
\hline
\end{tabular}

Source: Department of Social Welfare, Malaysia (2016)

Wafi and Sharifah (2017) state that the problems of unemployment, family conflict, the influence of illicit substances, evicted from homes, and the absence of beneficiaries are the leading causes of homelessness in Pulau Pinang. The findings of this study are in line with a survey by (2016), who also stated that the contributors to the problem of homelessness in Pulau Pinang are due to the absence of beneficiaries, misuse of illicit substances, mental health problems, evicted from homes and health problems. 
Asian Social Work Journal (ASWJ), Volume 6, Issue 5, (page 1 - 10), 2021

DOI: https://doi.org/10.47405/aswj.v6i5.179

\section{Literature Review}

\section{The Homeless}

Moorea et al. (2007) state that homeless people are people who are neglected by their community and the people around them. This group is excluded from society, and their state of homelessness usually led them to be insulted. These individuals are people with a variety of histories, which in turn that forced them to resort to being homeless. This group also realized that they had no social support in the face of the crisis that they had experienced. The state of homelessness and the activities related to it, in turn, have an impact on these individual's lives. The most affected area in their lives concerns their psychological and social aspects. Living a homeless life is considered as events that violate society's norms.

Megan (2014), in her study, has defined homeless people into three main categories:

i. No roof: Individuals who do not have a place and a roof to shelter at night, so they sleep in the streets, recreation areas, playgrounds, and roofless areas. Individuals who linger in a roofless public area are usually seen as homeless individuals.

ii. No house: Individuals who do not have a permanent home. They stayed in abandoned buildings, cars, pedicures, sidewalks, a place for them to rest in order to carry on with their daily routine the next day.

iii. Shelter house: Individuals are living in shelters such as rented areas allotted for the homeless, transit homes in which the homeless are allowed to stay for specific periods of time, temporary boarding houses.

Lukman and Asikin (2014) stated that the homeless are not deemed as the lowest rung in society (lumpenproletariat). But it is due their fate and life circumstances that they are forced to choose to live as a homeless in their lives. Education of Homeless Children and Youth (2009) claims that homeless individuals suffer from stress and have poor psychological functioning in their lives before they ended up becoming homeless. These people are helpless to cope with stressful situations such as poverty due to their lack of income to meet their own daily living needs.

People who are homeless are prone to various health problems. These include hepatitis C, HIV and AIDS, tuberculosis, and sexually transmitted diseases. This is due to the lifestyle of the homeless itself is exposed to an open environment that is unprotected from various health risks (Smollar, 1999). In addition, these groups are also seen as less concerned with the condition of their own wellbeing. The health services offered at local hospitals and clinics are not as accessed and utilized by them. A homeless usually did not practice a good personal hygiene and some of them admitted to not having bathe themselves for as long as three to four months at a period of time. Other sickly homeless also said that they did not bother to get treated from clinics or hospitals. Due to the absence of caring relatives or family members, they have no awareness of the importance of healthcare. Severe health conditions can cause psychological disorders such as depression, panic, and disruption of behavior change (Les et al., 2004).

According to Let at al. (2004), homeless people are also associated with individuals who are capable of contributing to violence in society. They condone to violence through various type of serious crimes such as thefts, murders, and abductions, which stemmed from the hardships they had suffered during their youth. Every crime that come to light in public eyes is more often than not negatively linked to the homeless. This connotation is being associated to them for several reasons: they are usually loners and spend their days in solitary manner. They lack compassionate feelings and empathy since they do not receive proper care and love from their family. They commit violence as a way of retaliating to things that took place in their past. As a result, they do not care for distorted general public's opinion that they are prone to get despite the fact the people in their surroundings are continually insulting and disrespecting them for their past and their state of homelessness. 
DOI: https://doi.org/10.47405/aswj.v6i5.179

Uncertainties in their daily lives can sometimes lead these homeless individuals to starvation. These people do not have enough nutrition needed in order to sustain their lives daily. Most of them resorted to eating spoiled food discarded in garbage and waste products, which are bad for human health. As a result, they will later suffer from health problems such as food poisoning. Though they are suffering from the pain, they forced themselves to deal with it alone without getting any treatment from the nearest hospital or clinic. Homeless people do not have enough money to cover the cost of paid hospital care (Thompson et al., 2002).

\section{The Homeless as People Who Had Given Up Hope}

Authors Own (2016) classifies these homeless people as desperate beings. From this study findings, it can be concluded that most homeless people choose to be alone because they experienced both social disconnections and were excluded from other people in their surroundings. Individuals interacts typically and connect with their surroundings. Social and relationships with one's surroundings are usually interconnected and can even be seen as a function that is vital in navigating life. This is clear when unavoidable situations occurred such as their dismissed or laid off, complicated family problems, divorce issues, poverty-related to the depletion of financial resources, the rise in the cost of living, behavioral matters involving alcohol and drug addiction, and health problems are reasons for conflicts in these homeless lives.

In facing such stressful situations, these groups are forced to a dead end in their attempt to find solutions to problems that are the result of their lack of good social support in their close environment. In these difficult situations, individuals are greatly in need of motivation and moral support from their social and surrounding systems so that they feel that there is still room to try and fix their situations. The goal is to ensure that this group can be guided to act and address their problems in a better manner. This is in line with Danczuk (2000) statement, who emphasized that the lack of motivation and support of the social structure would be further exacerbated by the fact that these groups would no longer be at ease and would not be able to withstand the problems that they are facing, which in turn led them to seek peace in an open and free environment.

For an individual who are homeless, his or her problem normally does not arise from a single source. Instead, they are exposed to a variety of problems at one time, thus refusing to engage in illegal crimes. For example, an individual who is terminated will be deprived of financial resources. The outcome from this issue could lead to monetary setback and in the future could encourage serious disagreements that ended up in marriage split up between spouses or cases of abandonment by close family members. This observation is supported by the respondents' feedback in this study, to which they confessed to experiencing problems as being stated above (Authors Own, 2016).

The inability to handle the problems they face properly will unbearable pressure on these people and then eventually leading them to resort to a new alternative by living as a homeless. It has also been supported by Smith and Ravenhill (2007) that individuals who are unable to manage stress and social and interactions with their surroundings well will turn to the environment as their refuge. The irrationality of the mind at that moment caused these people to be firm with their decisions. On the other hand, the social system in the homeless' community itself is seen as not working well, especially for closest family members.

Therefore, when this group of people resorted to being homeless, they are immediately cut off from any sort of communication with their family. Neglect from close family members has also made them street dwellers since they feel they are no longer needed by family members and are simply an unwanted burden to them. Ravenhill (2007) also argues that the instability of family relationships can lead individuals who have problems feeling overwhelmed and inadequate. It can also be the main reason in hindering attempts of rebuilding a strong bond with other people so that they can be helped. Ravenhill (2007) also sees this difficulty as the process of establishing the act of homelessness.

These homeless individuals situations can be promptly aided, and their status as homeless can be reversed if their family system are successful as a support system. Through a close two-way 
DOI: https://doi.org/10.47405/aswj.v6i5.179

communication it is shown that this method are able to restore their spirit and serve as a good advisor before any decision to lead a homeless life can be made. Demir and Weitekamp (2007) argue that good relationships will enhance one's self-esteem and happiness as they are a symbolic relationship and can meet the homeless' basic needs through social support and the help these people engage in a more secure environment. Family members should also provide some kind protection so that these people can feel safe and assured.

Inability to engage in a harmonious social relationship can stop them from socializing satisfactorily in a community. Harmony feelings in life cannot be reached due to negative synergies that surrounds their environment, which in turn stops them from living a healthier life after experiencing many problems and life interference. Deterioration in social relations and immediate surroundings has drastically reduced the group's inability to adapt to new changes. Here, the researchers see a potential relationship between the emotional and the psychosocial among the homeless with a sense of belonging. Ivan et al. (2004) stated that this problem would then cause the group to refuse to interact with the public due to their imperfect condition and way of living.

The problematic situation formed in these people's lives is closely related to the chronosystem introduced by Bronfenbrenner (1979). The chronosystem includes the beginning of events throughout the life cycle and the historical conditions that are triggered by the life journey of each individual. For example, in situations of abandonment resulted from family conflict or divorce, previous researchers have found that negative impressions often escalate into a contributing factor to an even worse situation. This is due to interactions in unstable and uncontrolled families (Santrock, 2009).

In addition, the lack of parties involved in a holistic and integrated approach to problem-solving in these problematic circumstances rendered their issues to be curbed and further isolated. At the same time, the homeless people unconsciously has created a new concept of thinking in their mind that no one is willing to help them as they have no importance to society. This is why these group of people do not place any hope in their social environment. It is even more disheartening that these people are not interested in getting any help and assistance unless there is someone who really committed in approaching them to offer their help. This group of people practices a 'wait and see' approach (Authors Own, 2016). This is in line with Cronley's (2010) statement that the absence of support from the concerned parties can be a contribution to the homeless phenomenon. Whereas Cohen and Crane (1996) posit that those who were separated or divorced or lost their social connections and lack of social support were found to be the reason for their state of homelessness.

Authors Own (2016) mentions that individuals who are depressed and troubled do not know where and to whom to seek help. It also shows that this group seems tired of the weak social systems in their surroundings. There are things they want to tell in the hopes that they can be helped. However, the reaction, stigma, and environmental discrimination received from their surroundings caused this group to harbor deep disappointment and pent-up feelings. Disappointment and sadness experienced are left alone to fester, and by doing so, they deny their right to return to normal life.

\section{Methods}

This study uses a phenomenological approach by conducting in-depth interviews. According to Cresswell (2007), phenomenological studies can provide in-depth knowledge and hands-on experience of the issues being studied. According to Donalek (2004), studies using a phenomenological approach are used to study the life experience of an individual through transparent storytelling based on experiences experienced by said informants. According to Alan and Robert (1999), qualitative studies are more sensitive to the specific environment studied and are seen to be holistic or more comprehensive towards the subject matter.

The study is conducted by interviewing 20 informants using sampling techniques based on phenomenological design. Cresswell (2007) argues that phenomenological research design deals primarily with small sample sizes because the study's features are more in-depth in terms of data 


\section{Asian Social Work Journal (ASWJ), Volume 6, Issue 5, (page 1 - 10), 2021 \\ DOI: https://doi.org/10.47405/aswj.v6i5.179}

collection. Five (5) to 25 informants are sufficient to develop a clear understanding of the subject under consideration. Informants in this study consisted of various races, such as Malay, Chinese, and Indian. This study was conducted around the Georgetown area in Penang with a focus on major locations that these homeless tend to assemble. Among these locations are the Kapitan Keling Mosque, jetties, KOMTAR, bus stops, and Chulia expressway.

The method of data collection for this research was conducted through in-depth interviews using semistructured and open-ended questions. According to Shank (2002), open-ended interviews were used in qualitative studies to enable informants to share their experiences. In-depth interviews were conducted with the use of the Malay language and the slang terms or "local dialects" to facilitate the informants' better understanding of the questions posed by the researcher.

Neuman (2003) argues that the responsibility of researchers is to protect the confidentiality of informants. Researchers should ensure that the information received is not exposed to others. Burns and Grove (2001) require researchers to maintain confidentiality while conducting qualitative research. To protect the confidentiality of personal information and informants, all informants involved are represented by a code of R1 to R20.

\section{Results}

The study was done by conducting several in-depth interviews with twenty (20) volunteers. Informants who had participated in this study consists of twelve (12) Malays informants, four (4) Chinese informants and four (4) Indian informants. In terms of gender, the research informants consisted of seventeen (17) men and three (3) women. In this study, the researcher are focused on the support system available to the respondents. The purpose of this is to see how well the support system around the respondent works in assisting the informant.

Most respondents stated that they did not receive help or support of any kind from family members or peers whether in the form of welfare as well as emotional support. They were not immediately cared for by family members and close friends. This leaves them with little hope that family members or peers can help to improve their quality of life. This has led the interviewer to go through their day-today life without relying on anyone's goodwill.

The following are some of the statements shared by the informants in this study. In the excerpts below are parts of the results from the interview with the informants involved in this study.

"...Yes, there's none... it's okay, even I didn't ask from them... I didn't ask from them... there's no need to go to such trouble... if they won't reach out to me, it will ended up hurting me later... (Informant 1)

"... There's none... why should they help... they didn't even like me... I'm poor. When I had fallen into a difficult time back then, they refused to help me. Now things have come to this, do you think they will come to help? They would pray for my early demise instead... I don't need it... I am comfortable with my life right now as it is. It's enough that I have many friends in the same boat as I am here. We can chat together. If there's money, I will eat ... if there's no money I can just stay here. Those here who's just like me is like family to me." (Informant 2)

"...I don't get along with them, how they will offer help... its better that they didn't help... even if they are helping, they will surely bring up the past later... I guess they think of me as a no-good trash... I guess it must be so... just think... if they thought of me as a human... or as their younger sibling ka... their brother ka... if they knew that I am experiencing hardship to the point that I don't even have food to eat... They will not hesitate to help... but instead, there is no help at all.. my current life is easier for me... here I got friends that I can talk to. Share... share... I 
DOI: https://doi.org/10.47405/aswj.v6i5.179

go to work and then I come back... I can sleep everywhere I please... I am used to it..." (Informant 4)

"... They're ashamed to come here to look for me... even if they want to help me... I don't care to accept it...my wages is enough to sustain my life... it's okay if they don't come to visit me... damn if they come... I dare to cut my fingers... that they surely won't come at all... they are not willing to take care of me... to come here to offer for help ka... there's enough that there's only me here, family is useless anyway. "(Informant 6)

"I've got friends...their circumstances are pretty similar to mine. There's those with even worst situation, but they are good...we gets each other just like blood relative do... You don't even have to mention my siblings... It's troublesome to talk to brainless people. You don't have to be troubled. There's none... nobody will come. I am a no-good man... It's difficult to explain". (Informant 7)

"... There's none... who will take a liking to someone like me... if anything, they are more prone to badmouth me instead. It's useless... hence I give up. Indeed, one shouldn't put their hope that people will come to help. They won't come for sure. Let me live alone, even die alone. If passersby find me, they will report it to the police and then bury me. Simple... I have not but a few friends... they're poor like me as well... We can talk to each other... some were nice folks... I sought them to converse with." (R11)

According to Wain et al. (2011), social support provided by family members had always proven to be a complicated matter to discuss in a study. Families, especially parents, are an important element in helping to provide moral support to family members who are facing hardship and hardship, including those who have been resorted to going homeless. Individuals who move out of their own homes and flee from their families by choosing to go homeless are often individuals left with no family support (Bao, Whitbeck, \& Hoyt, 2001).

This situation has caused homeless people to feel alienated from their family that should be their backbone in providing support for them in order to remain strong in the face of life hardship and difficulties. In this regard, they are seen as carving their own path and trying to sever relationships with family members because they themselves do not seem to have meaning in their families' lives. Karabanaow (2006) states that individuals who do not receive social support from family members will reject their close family networks and turn to their peers for some semblance of social, emotional and physical support. In trying to complement each other's needs, they will communicate and rely on each other's support without expecting help from others outside of their circle. They will develop a more consistent and meaningful "street connection" than their real families. This relationship acts as a substitute for social relationships such as parents and other family members (Bender et al., 2007).

\section{Discussion}

Despite living in a state of homelessness, this group is seen to be needing emotional, physical and social support as any other individuals so that they can live a normal and orderly life. The difficulties and hardships faced by being abandoned by their family members made them resorted to go homeless as a way break the family bond with their nuclear family due to problems arising from the family itself. According to Thompson et al. (2010) an individual will cut themselves off from their immediate kin and family institution as they face hardship, abuse, violence and lack of social support. As a result, the researcher found that the group seemed to give up on their fate. The group also showed a sense of hopelessness upon seeing that all their efforts that they had made could not improve their quality of life. Pressure from a various angles as well as difficulty in finding a good place to shelter makes this group more inclined to go homeless. 
Based on the interviews conducted, the informant was seen as not expecting any kind of social support from their family as they should have. In fact, this group is not seen as one who asks begs others to help or have pity on them. According to Osborne (2002), homeless people are not beggars. The pain inflicted family members lead them to lose touch with their family members even though their lives are scarce and exposed to various dangers while living on the streets.

In addition, based on the results of the interview, several informant stated that friends are seen as a place to share problems and communicate with each other. However, their friends also had the same fate as being homeless. Only those in the same situation can feel and understand their way of lives respectively. Relationships between those in the same boat are seen as supporting each other in their own way. According to Tyler et al. (2004), this relationship leads to a close and familiar relationship. It also aims to combat loneliness, isolation, and feeling alone when there is no family members who cares. This group of people will began to put trust in street friends as they think their peers are more aware of their burdens and state of emotions and thus they feel safer when they are with them.

Interviews with informants also found that the group considered these homeless friends as their closest relatives. They even have a lot of friends. The findings of the researcher also discovers that peers were concerned about their safety and circumstances during an interview with the informants. According to Karabanaow (2006), these people have lived longer on the road and thus have had longer and larger exposure and bigger contact and are more likely to risk certain act of misconduct as a result from being stressed. A large peer's network reinforces their attitude and raises their confidence in the support and attention they receive.

From the findings on this research, the researcher had observed that the homeless form connections with their street friends and rely on them as a way of a support system to cope from the harsh conundrum in their daily lives. Nevertheless, there is still remain to be a concern as the established relationship could result in a shift in the homeless' behavior such as the consumption of illicit substances when they are encouraged or influenced by their street friends to try it as a way to escape their current reality. In order to be accepted by their peers, they will later ended up consuming and got addicted to the illegal substances. Findings in this research is seen in a similar vein as those of Tyler et al. (2004) which attested that homeless individuals are helpless to the pull of drug and alcohol abuse when they are bonding with their street friends in a get together activities .

Therefore, these findings show that every behavior, thought, and feeling experienced by these groups of people is driven by the influence of the environment, desperation in life, as well as the failure of the social system and environment in order to help them to function properly and effectively. These series of emotional breakdown in turn affects the outcome one makes in future decision making. Similarly, western scholar Berne (1964) who shared the same perspective as the researcher elaborated further that environmental conditions can influence a person's judgement. Each kind of behavior serve a specific purpose behind its manifestation. Every established or accomplished objectives are connected to a learning process, this learning then became significant to one's experience, which in turn left a deep impression in our brain subconscious and thus formed a "cognitive map" in one's mind, a map that will steer us to predict what can be expected or anticipated for in our future.

Therefore, the social and environmental ties for these homeless people need to be restored and rebuilt. By restoring the social structure of these groups, it is seen that they can regain their confidence in normalizing their lives. This needs to be implemented so that a life full of various risks can be changed. At the same time, it can avoid the emergence of new issues that make the situation worse (Authors Own, 2016).

\section{Conclusion}

This study has shown that homeless people in Georgetown, Penang are individuals who find themselves abandoned, unappreciated, and unwanted by their families. These feelings have caused these groups to isolate themselves from their family members. Previous conflicts have led them to live 


\section{Asian Social Work Journal (ASWJ), Volume 6, Issue 5, (page 1 - 10), 2021 \\ DOI: https://doi.org/10.47405/aswj.v6i5.179}

a miserable life without the aid of any social support from family members as a close collateral source. The decision to live a solitary and exiled life has led these individual into a homeless life that is full of misery and deprived from basic materials human needs in order to survive. Living in such manner also made them more vulnerable to unexpected threat and dangerous risks and ordeals.

The study also revealed that those in the same boat or "street friends" serve as individuals who care for and support each other. This has led to a close relationship and unity among them, which is a necessity for them to live their life on the street. This relationship has little to no effect on individuals dealing with addiction to illicit substances such as alcohol, drugs, and substance abuse and potential abuse. This tendency is seen as repayment or an act of appreciation for the attention and support that their peers have given them. If this continues, it will later contribute to more social problems among the homeless. It will strengthen the public's negative perception that these homeless people are individuals who are capable of threatening the peaceful life of other residents.

Consequently, it is suggested that an in depth and comprehensive study of how these "street friends" is able to influence their homeless peers in term of their behavioural change is done in the future so that we can attempt to intervene these negative behaviours from an earlier stage, and finally to create a good mechanism that can help the homeless to improve their ability to better the quality of their lives by utilising their maximum potential and strengths without having to depend on other's help.

\section{References}

Authors Own (2016). Dinamik kehidupan golongan gelandangan di Pulau Pinang. Ph.D Dissertation. Universiti Sains Malaysia.

Alan, B., \& Robert, G. B. (1994). Development in qualitative data analysis: An introduction. Retrieved from https://www.taylorfrancis.com/books/e/ $9780203413081 \quad$ /chapters/ $10.4324 / 978020343081-5$.

Bao, W., Whitbeck, L., \& Hoyt, D. (2001). Abuse, Support, and Depression among Homeless and Runaway Adolescents. Journal of Health and Social Behavior, 41, 408-20.10.2307/2676294.

Bender, Kimberly, Thompson, Sanna, McManus, Holly, Lantry, Janet, \& Flynn, Patrick. (2007). Capacity for Survival: Exploring Strengths of Homeless Street Youth. Child \& youth care forum. 36. 25-42. 10.1007/s10566-006-9029-4.

Bronfenbrenner, U. (1979). The ecology of human development: Experiments by nature and design. Cambridge, MA: Harvard University Press.

Burns, N., \& Grove, S.K. (2001). The practice of nursing research: Conduct, critique, \& utilization (4th ed.). Philadelphia: Saunders.

Cohen, C.I., \& Crane, M. (1996). Old and homeless in London and New York City: A cross national comparison. In D. Bhurga (Ed.), Homelessness and mental Health (pp. 150 169). London: Cambridge University Press.

Creswell, J. W. (2007). Qualitative inquiry and research design: Choosing among five approaches $\left(2^{\text {nd }}\right.$ ed.). Thousand Oaks, CA: Sage.

Cronley, C. (2010). Unraveling the social construction or homelessness. Journal of HumanBehavior in Social Environment, 20, 318-333.

Danczuk. (2000). Walk on by...Begging, street drinking and the giving age. London: Crisis.

Demir, M. \& Weitekamp, L. A. (2007) I am so happy couse today I found my friend: Friendship and personality as predictors of happiness. Journal of Happiness Studies, 8, 181-211.

Department of Social Welfare Malaysia. (2015). Retrieved from http://www.jkm.gov.my /jkm/uploads/files/penerbitan/Buku\%20JKM\%202015\%E2\%80\%A2Final.pdf.

Donalek, J. G. (2004). Phenomenology as a qualitative research method. Urologic Nursing, (6), 516517.

Education of Homeless Children and Youth. (2009). The National Coalition for the Homeless.

Ivan, I., Osinkii, Khabareva, M. I., \& Baldaeva, B. I. (2004). The homeless: The social lowerdepth of society. Sociological Research, 43(3), 54-66. 
DOI: https://doi.org/10.47405/aswj.v6i5.179

Karabanow, J. (2006). Becoming a street kids. Journal of Human Behavior in the Social Environment, 13(2).

Les, B.W., Xiaojin, C., R.H., Kimberly, A.T., \& Kurt, D., J. (2004). Mental disorder, subsistence strategies, and victimization among gay, lesbian, and bisexualhomeless and runaway adolescents. J Sex Res, 41, 329-342.

Lukman, Z.M. \& Asyikin, S.S. (2014). Gelandangan atau lumpenproletariat? Memahami masalah kemiskinan bandar dan fenomena tidur di kaki lima bangunan. Proceeding of the 50th Anniversary Celebration International Conference.

Megan, R. H. (2014). The culture of homelessness: An ethnographic study. PhD Dissertaions, London School of Economic.

Moore, G., M. Gerdtz, \& Manias, E., (2007). "Homelessness, health status, and emergency department use: An Integrated Review of the Literature" Australasian Emergency Nursing Journal, 10, 178-185.

Neuman, W. L. (2003). Social research methods: Qualitative and quantitative approaches (5th ed.). Boston: Allyn \& Bacon.

Osborne, R. E. (2002). 'I May be Homeless, But I'm Not Helpless": The Costs and Benefits of Identifying with Homelessness. Self and Identity, 1 (1), 43-52.

Santrock, J. W. (2009). Life-span development. (12th ed.) New York: McGraw Hill Higher Education.

Shank, G. (2002). Qualitative research: A personal skills approach. Upper Saddle River, NJ: Merrill, Prentice Hall.

Smith, J. \& Ravenhill, M. (2007). What is homelessness? A report on the attitudes of young people and parents on risk of running away and homelessness in London. Retrieved from www.centrepoint.org.uk/documents/Centrepoint_What is Homelessness.

Smollar, J. (1999). Homeless youth in the United States: Description and developmental issues. New Directions for Child \& Adolescent Development, 85, 47-58.

Theresa, K. (2006). Loneliness, homelessness a toxic mix. Street Roots Newspaper.

Thompson S., Pollio D., Constantine J., Reid, D., \& Nebbitt, V. (2002). Short- term outcomes for youth receiving runaway and homeless shelter services. Research on Social Work Practice, 12, 589-603.

Thompson, S., Bender, K., Windsor, L., Cook, M., \& Williams, T. (2010). Homeless youth: Characteristics, contributing factors, and service options. Journal of Human Behavior in The Social Environment, 20, 193-217.10.1080/10911350903269831.

Tyler, K. A., Hoyt, D. R., Whitbeck, L. B., \& Cauce, A. M. (2001). The impact of childhood sexual abuse on later sexual victimization among runaway youth. Journal of Research on Adolescence, $11,151-176$.

Wafi, M,. \& Sharifah, R. (2017). Memahami permasalahan golongan terpinggir di bandar: Kajian Kes Gelandangan Di George Town, Pulau Pinang, 5, 78-94.

Wain, R., Wilbourne, P., Harris, K., Pierson, H., Teleki, J., Burling, T., \& Lovett, S. (2011). Motivational interview improves treatment entry in homeless veterans. Drug and Alcohol Dependence, 115, 113-119. 